\title{
Prevention of Mother to Child Transmission (PM TCT) Program at Paropakar Maternity and Women's Hospital: A Review
}

\author{
Shrestha M, Chaudhary P, Tumbhahangphe M, Poudel J \\ Paropakar Maternity and Women's Hospital, Kathmandu, Nepal
}

\begin{abstract}
Aims: Vertical transmission from mother to fetus is the main route of HIVinfection among children. This study is an effort to review utilization of prevention of mother to child transmission (PMTCT) services by pregnant women seeking care in Paropakar Maternity and Women's Hospital (PMWH).
\end{abstract}

\begin{abstract}
Methods: Case records of 165 pregnant women with HIV positive status who delivered at Paropakar Maternity and Women's Hospital, Kathmandu from April 2005 to Dec 2011 were reviewed. Demographic profile of these women and interventions to prevent mother to child transmission (MTCT) including antiretroviral prophylaxis (ARV), mode of delivery, infant feeding practice as well as HIV status of their children were recorded.
\end{abstract}

Results: Hospital records showed 109262 antenatal attendees and 120823 deliveries including 165 HIV infected women who delivered in this facility. Prevalence of HIV infection among antenatal attendees was $0.11 \%$ and $0.13 \%$ in hospital deliveries. Migrant worker spouse (44.2\%) was the main source of infection in their wives. Eighty eight (55.7\%) out of 150 eligible women received ARV drugs and $97 \%$ babies received antiretroviral prophylaxis . Spontaneous vaginal delivery occurred in $60 \%$ women and caesarean section performed in the rest. While $60.8 \%$ women opted for exclusive breast feeding, remaining $39.2 \%$ chose formula feeding. For prophylaxis of opportunistic infection, Cotrimoxazole was given to $70.3 \%$ children. The incidence of HIV infection in babies born to HIV infected mother was $5.1 \%$.

Conclusions: Integrating PMTCT services into existing maternal and child health system can significantly reduce perinatal transmission of HIV infection to children.

Keywords: Antiretroviral therapy, breast feeding, mode of delivery, mother to child transmission, prevention

\section{INTRODUCTION}

The first case of HIV/AIDS was reported in 1988 in Nepal. ${ }^{2}$ Currently, an estimated number of HIV infected adults and children is 63,528 and $29 \%$ of them are women, among which $90 \%$ belongs to reproductive age group. ${ }^{3}$ According to WHO definition, HIV infection transmitted from HIV infected mother to her child during pregnancy, labor, delivery and breast feeding is termed as Mother to child Transmission (MTCT). 2, 3, 4, 5 Perinatal transmission is the major route of HIV infection in children of third world countries and $90 \%$ of MTCT occurs during labor due to contamination of baby with vaginal secretion. ${ }^{3,4}$ Advanced maternal HIV disease, decreased CD4 count and increased viral load increase the risk of MTCT significantly. Most of the infected infants become symptomatic by 6 months of life and without treatment, one third will die before their first birthday. ${ }^{1,3}$ Moreover, $50 \%$ of them die before their 2nd birthday as risk of MTCT ranges from 20-45\% without intervention. $^{3}$

\section{CORRESPONDENCE}

Dr. Madhu Shrestha, MD

Department of Obstetrics and Gynecology

Paropakar Maternity and Women's Hospital

Kathmandu, Nepal

Phone: 9841286867

Email: shresthamadhu74@gmail.com
In 2001, the UN General assembly set a target for $80 \%$ coverage of pregnant women and their children to have access to prevention, treatment and care to reduce pediatric HIV infection by $50 \%$ by $2010 .{ }^{4}$ Due to wide coverage of strongly effective ARV and obstetric intervention, MTCT transmission rate in USA and Europe has dropped down to $2 \% .^{5,6,7}$ PMTCT program was introduced in the late $1990 .^{6}$ But, unfortunately, in spite of availability of ARV drugs, global coverage of PMTCT services is still low as most of the infected women are from developing countries, where uptake of this program is not well scaled up. Only $45 \%$ of HIV positive women in low and middle income countries had antiviral prophylaxis for PMTCT in 2008. ${ }^{5}$

Estimated prevalence of HIV infection among antenatal attendees in Nepal is $0.2 \% .^{3,8,9}$ Government of Nepal launched the "Comprehensive PMTCT Services", for the first time in the year 2005 at Paropakar Maternity and Women's Hospital. This service package includes voluntary counseling and testing (VCT), ARV prophylaxis 
of pregnant women and for HIV - exposed babies, infant feeding counseling and support, safe obstetric care, family planning and referral care and support of HIV infected women and children.

According to first national guideline of Nepal (2005), single dose of Tab. Nevirapine (NVP) $400 \mathrm{mg}$ was given to pregnant women at the onset of labor and neonates as early as possible (within 72 hrs). In 2008, expanded prophylaxis (Zidovudine, Lamivudine and Nevirapine) was started from 28 weeks of gestation and after birth; baby was given Nevirapine and Zidovudine. In 2010,ARV guideline has been reviewed again and from 2011, triple drug therapy including Zidovudine or Tofinavir if $\mathrm{Hb}$ is less than 8gm\%), Lamivudine and Efavirenz from 14wks till delivery, and continuing in postpartum 1year till cessation of breast feeding followed by Efavirenz one week with subsequent 1 week Zidovudine and Lamivudine was recommended. Nevirapine is given for six weeks for breast fed and for seven days only, if replacement feeding is chosen. Mother and baby are followed up monthly from 45 days onward every month till 18 months. . Cotrimoxazole prophylaxis to baby is started from 45 days of birth to 18 months. PCR test to baby is offered at 6weeks followed by antibody test at 9 months and confirmatory antibody test is done at 18 months of birth. If infant death occurs, it is recorded. ${ }^{3,7-9}$

The aim of this study was to review the impact of PMTCT services to prevent pediatric HIV.

\section{METHODS}

This was a retrospective review of medical records of HIV infected women who delivered babies at PMWH between April 2005 to December 2011(seven years and nine months).Ethnicity, gravidity, maternal age, paternal risk factors, mode of delivery, prophylactic measures given to mother and baby, type of infant feeding, cotrimoxazole prophylaxis, follow up and determination of HIV -status of infant after completion 18 months of lives were analyzed.

\section{RESULTS}

From April 2005 to December 2011(7 yrs 9 months), 109262 pregnant women attended the antenatal clinic. Only 96572 (88.4\%) accepted pretest counseling and $82496(85.4 \%)$ of them had undergone HIV test. There were 126 positive cases. By VCT, 81(64.3\%) HIV positive cases were identified, $45(35.7 \%)$ cases being referred from outside. Fifteen (11.9\%) were drop outs and 111(88.9\%) booked cases had delivered in this hospital. During same period, 120823 deliveries were recorded and 165 of them found to be HIV positive, $111(67.3 \%)$ being booked and $54(32.7 \%)$ being unbooked who were identified after routine investigation. Incidence of HIV was less than one percent in antenatal attendees and deliveries (Table 2, 3.).
Table 1. Risk factors for Female HIV Infection

\begin{tabular}{llll}
\hline Cause of HIV+ & No. & & (\%) \\
\hline Husband & 99 & 60.0 \\
Prev. husband & 23 & 13.9 \\
Ex-partner & 10 & 6.1 \\
Sex worker & 12 & 7.3 \\
Multiple partner & 9 & 5.5 \\
Drug user & 5 & 3.0 \\
Risk unknown & 6 & 3.6 \\
Sexual assault & 1 & 0.6 \\
Total & 165 & 100 \\
\hline
\end{tabular}

Table 2. Proportion of HIV+ Pregnant women and infants

\begin{tabular}{lllllllll}
\hline Year. & $\begin{array}{l}\text { ANC } \\
\text { attendees }\end{array}$ & $\begin{array}{l}\text { Pretest } \\
(\%)\end{array}$ & no. & HIV test $\%$ & \multicolumn{2}{l}{$\begin{array}{l}\text { HIV+ } \\
\text { infants (\%) }\end{array}$} \\
\hline 2005 & 4820 & 2979 & 61.8 & 2084 & 70.0 & 10 & 0.5 \\
2006 & 10266 & 9986 & 97.3 & 3996 & 40.0 & 17 & 0.4 \\
2007 & 11015 & 9567 & 86.9 & 9520 & 99.5 & 14 & 0.1 \\
2008 & 17779 & 15107 & 85.1 & 14270 & 54.5 & 12 & 0.08 \\
2009 & 22285 & 21539 & 96.7 & 19217 & 89.2 & 20 & 0.1 \\
2010 & 25018 & 23309 & 93.2 & 21119 & 90.6 & 21 & 0.09 \\
2011 & 18079 & 14085 & 77.9 & 12288 & 87.2 & 32 & 0.3 \\
Total & 109262 & 96572 & & 82494 & & 126 & \\
\hline
\end{tabular}

Table 3. Proportion of HIV+ women in hospital delivery

\begin{tabular}{llll}
\hline Year & $\begin{array}{l}\text { Total } \\
\text { deliveries }\end{array}$ & Delivery in HIV+women \% \\
\hline 2005 & 7065 & 6 & 0.08 \\
2006 & 17900 & 17 & 0.09 \\
2007 & 18186 & 20 & 0.1 \\
2008 & 17824 & 20 & 0.1 \\
2009 & 18196 & 32 & 0.2 \\
2010 & 21458 & 34 & 0.2 \\
2011 & 20194 & 36 & 0.2 \\
Total & 120825 & 165 & \\
\hline
\end{tabular}

By ethnicity, 61 (37.0\%) women were Mongolian ethnic group and 108(65.5\%) were primigravidae, 153 (92.7\%) women were housewives 12 (7.3\%) were sex workers. By profession, partners of $73(44.2 \%)$ pregnant women were migrant workers. The mean age of women was $26.6 y r s$.

As basic investigation, CD4 count was done in 134(81.2\%) hospital delivered women. Out of 165,158 pregnant women were eligible for ARV prophylaxis as seven were known IUFD. However, only $88(53.9 \%)$ received ARV prophylaxis as 45(28.5\%) were already on ART. Unfortunately, 25(15.8\%) pregnant women missed prophylaxis due to different reasons, 4 of them being home delivery and three were premature deliveries. 
Fifty (31.6\%) pregnant women and babies received single dose of Nevirapine. Thirty (19.05\%) were given combined prophylaxis and their babies received Nevirapine and Zidovudine. Similarly as $45(28,5 \%)$ pregnant women were already on ART and babies born to 38 women were given Nevirapine and Zidovudine and only Nevirapine in 7 babies. Triple drug ARV therapy was given in 8 mothers and their babies received only Nevirapine for 6 weeks. Zidovudine (Table 4, 5).

Table 4. Relation between maternal ARV prophylaxis and infant HIV status

\begin{tabular}{lll}
\hline ARV & $\begin{array}{l}\text { No.of mother (\%) } \\
\text { On ARV }\end{array}$ & HIV+ infants (\%) \\
\hline NVP & $50(31.6 \%)$ & $2(4.0)$ \\
$\begin{array}{l}\text { Combined } \\
\text { prophylaxis }\end{array}$ & $30(19.0 \%)$ & \\
ART & $45(28.5 \%)$ & $1(2.2)$ \\
Triple therapy & $8(5.1 \%)$ & \\
Missed & $25(15.8 \%)$ & $3(12.0)$ \\
Total & 158 & $6(18.2)$ \\
\hline
\end{tabular}

Table 5. Relation between perinatal ARV prophylaxis and infant HIV status

\begin{tabular}{lll}
\hline ARV & $\begin{array}{l}\text { No. of infants on } \\
\text { ARV }(\%)\end{array}$ & HIV+infant \% \\
\hline NVP & $65(41.2 \%)$ & $2(3.1)$ \\
NVP+ZDV & $89(56.3 \%)$ & $2(2.2)$ \\
Missed & $4(2.5 \%)$ & $2(50)$ \\
Total & $158(100)$ & $6(55.3)$ \\
\hline
\end{tabular}

Out of 165 deliveries, 99(60.0\%) women delivered vaginally and $66(40.0 \%)$ had Caesarean section (Table 5). Regarding feeding, 96(60.8\%) mothers opted for breast feeding and 62(39.2\%)-formula feeding (Table 6). Seventy babies $(44.3 \%)$ received Co-trimoxazole as prophylaxis against opportunistic infection.

Table 6. Mode of delivery in HIV+ pregnant women

\begin{tabular}{lll}
\hline Type of delivery & $\begin{array}{l}\text { No.of } \\
\text { deliveries(\%) }\end{array}$ & $\begin{array}{l}\text { No. of HIV+ } \\
\text { Infants \% }\end{array}$ \\
\hline $\begin{array}{l}\text { Vaginal } \\
\text { instrumental }\end{array}$ & $99(60.0)$ & $3(3.0)$ \\
Emg.c/s & $31(18.8)$ & $3(9.7)$ \\
Elective c/s & $35(21.2)$ & - \\
Total & $165(100)$ & $6(12.7)$ \\
\hline
\end{tabular}

There were 7 intrauterine fetal death (4.2\%), 7 (4.2\%) neonatal death and $11(6.7 \%)$ babies died between 2 to 18 months of life, before confirmatory antibody test. Twenty three (13.9\%) babies were lost to follow up. The remaining $117(70.9 \%)$ babies were followed and confirmatory antibody test was done at completion of 18 months. There were $111(94.9 \%)$ negative and six $(5.1 \%)$ HIV positive tests among tested children.

Table 7. Type of feeding in HIV exposed babies

\begin{tabular}{lll}
\hline Type of feeding & No. of infants & $\begin{array}{l}\text { No. of HIV+ve } \\
\text { infants \% }\end{array}$ \\
\hline Breast feeding & 96 & $2(2.1)$ \\
Formula feeding & 62 & $4(6.5)$ \\
Total & 158 & $6(8.6)$ \\
\hline
\end{tabular}

Among 50 pairs of mother and child, who received Nevirapine as single dose, 2(4.0\%) were reported HIV positive. Both of them were delivered abdominally on obstetric indication (fetal distress). One baby was breast fed, another one formula fed. Both mother's CD4 count was above 300 and both babies were given Cotrimoxazole for 18 months. One mother was having regular ANC checkup in this hospital, but another case was detected in latent phase of labor (Table 7).

Two children, who were found to HIV infected as their mother missed prophylaxis, were given Nevirapine and Zidovudine. One of them was born by c-section and formula fed and the other was delivered vaginally and breast fed. One baby got Cotrimoxazole for 18 months and another baby missed it. CD4 count of both mothers was above 300 (Table 7).

Out of 45 babies, one baby whose mother was on ART, was found HIV positive As ARV prophylaxis this baby was given Zidovudine and Nevirapine. This baby was born vaginally and formula fed and received Cotrimoxazole for 18 months. CD4 count of mother was above 300 (Table 7).

One pair of mother and baby missed prophylaxis and baby tested positive. This baby was born vaginally; formula fed and received Cotrimoxazole for 18 months. CD4 Count of his mother was more than 300 .

All children of mothers who received combined prophylaxis were found to be HIV negative (Table 7).

\section{DISCUSSION}

With the help of trained counselors and making HIV test a routine component of antenatal care large improvement was noted in terms of program indicators in South Africa.10 Likewise, through participatory approach, uptake of PMTCT service was greatly increased from $45 \%$ to $90 \%$ in the first year and $99 \%$ by third year of study in Zambia. ${ }^{6}$ Another study conducted in seven health centres in Kenya reported the high acceptance of PMTCT services depends upon the active participation of field and health centre staff and follow up of all mothers. ${ }^{11}$ High uptake of HIV test was also reported by Lilonge and Malawi following introduction of 
HIV test as routine antenatal care. ${ }^{4}$ Interestingly, in Nigeria, there was high acceptance of counseling and testing but low uptake of ARV prophylaxis. ${ }^{5}$

This review also indicates that from 2005 to 2011 the uptake VCT is satisfactory. Acceptance of pretest counseling ranged from $61 \%$ to $97 \%$ and $40 \%$ to $99 \%$ of them underwent the test for HIV. However there was some fluctuation from time to time which could be due to inadequate trained staff, poor co-ordination between service providers and management body or other managerial or technical problem.

Introduction of PMTCT program increased utilization of ARV prophylaxis from $29 \%$ to $66 \%$ in Zambia and $56 \%$ to $96 \%$ in South Africa. ${ }^{6,10}$ Similar improvement was observed in Kenya. ${ }^{11}$ Similarly a series of studies in Africa and Asia found that even a short course of ARV prophylaxis was able to reduce MTCT to $10-15 \%$. HIVNET 012 study also showed that single dose of Nevirapine to mother and infant halved the risk of transmission. ${ }^{4,12}$ In this review study, 55\% pregnant women and $97 \%$ children accepted the prophylaxis. It also found that use of any regimen, ranging from single dose Nevirapine to triple drug regimen was able to reduce MTCT less than $5 \%$.

HIVNET012 trial in Uganda reported that single dose of Nevirapine to mother and baby halved the MTCT. ${ }^{3,9}$ In our hospital such regimen resulted into vertical transmission in two (4\%) children. In Thailand, combined prophylaxis reduced $\mathrm{MTCT}<2 \%$.Similarly, Triple drug regimen was found to be safe and effective in high resource and some African countries. ${ }^{3}$ Our review also found that no babies found to be infected, whose mother got combined or triple therapy prophylaxis.

Studies done by international Perinatal HIV group and European Mode of Delivery Collaboration reported that vertical transmission was halved by caesarean section. But, Strangers and colleagues recommended to limit planned caesarean delivery as combined ARV prophylaxis can reduce $\mathrm{MTCT}$ to less than $2 \% .{ }^{11} \mathrm{We}$, too, observed no significant difference in HIV incidence in babies born by vaginal route and emergency caesarean section. However, all children born by planned c-section were found to be HIV negative. These findings might be related to the availability of counselors and ARV drugs during visiting hour, effectiveness of VCT, adherence and motivation of women themselves.

In well resource countries, breast feeding is not recommended, as it significantly increases post natal transmission. ${ }^{3,11}$ The six week extended Nevirapine (SWEN) study found that the additional six week Nevirapine regimen to breast fed babies reduced vertical transmission by $50 \% .{ }^{3}$ But we found that out of six HIV positive children, four (66.7\%) were formula fed. Missing ARV prophylaxis, non-adherence, non potent drugs and managerial difficulties could be the reason for such a contradictory finding.

\section{CONCLUSIONS}

PMTCT service has been consistently provided since last six years in the hospital and number of HIV positive pick up rate is increasing. Primary source of HIV transmission was from husband in $3 / 4$ th of cases.

\section{REFERENCES}

1. National Guideline on Anti-Retroviral (ARV). Government of Nepal. Ministry of Health and Population. National Centre for AIDS and STD control; 2005. p.1-23

2. National Guidelines. Prevention of Mother- to-child transmission of HIV in Nepal. Government of Nepal. Ministry of Health and Population. National Centre for AIDS and STD control. 4th ed. 2011 p.1-65.

3. McIntyre JA. HIV and pregnancy-the African perspective. Recent advances in obstetrics and gynecology. 24th ed. Jaypeebrothers; 2009.p.13-26.

4. Olanrewaju AM, Ola FA, Akintunde AE, Ibrahim B, Ibiyemi F. HIV voluntary counseling and testing of pregnant women in primary health care centers in Ilesa, Nigeria. The internet Journal of Third World Medicine. 2007; 6(1)

5. Tropey, Kabaso M, Kasonda P, Dirks R, Bweupe M, Thompson $\mathrm{C}$, et al. Increasing the uptake of prevention of mother-to-child transmission of HIV services in a resource-limited setting. BMC Health Serv Res. 2010;10:29.

6. National Guidelines. Prevention of mother- to-child transmission of HIV in Nepal. Ministry of Health and Population. National Centre for AIDS and STD control; 2005. p.1-39.

7. National Guidelines. Prevention of mother- to-child transmission of HIV in Nepal. Ministry of Health and Population. National Centre for AIDS and STD control; 2008. p.1-65.

8. Doherty T, Chopra M, Nsibande D, Mngoma D. Improving the coverage of the PMTCT programme through a participatory quality improvement intervention in South Africa. BMC Public Health. 2009;9:406

9. Songok EM, Fujiyama Y, Tukei PM, Vulule JM, Kiptoo MK, Adungo NO, et al. The use of short-course Zidovudine to prevent perinata transmission of human immunodeficiency virus in rural Kenya. Am J Trop Med Hyg. 2003;69(1):8-3.

10. Sharma S. Preventing mother to child transmission of HIV. JNMA J Nepal Med Assoc. 2003;42:380-2.

11. Cunningham FG et al .W.In: Williams Obstetrics. 22nd ed.McGRAWHILL.2005.p.1310-17.

12. Hall HM. Pregnancy and antenatal care. In: ChamberlineG Steev P. editors.Turnbull Obstetrics.3rded.Churchill Livingstone: 2001.p.105$111,372-3$. 